\title{
Patents and the quality, safety and efficacy of medicines
}

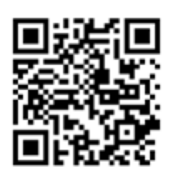

A patent represents a right or title conferred by a government authority granting an inventor a limited period of exclusive use of a patented invention, in return for full public disclosure of the invention. ${ }^{[1]}$ The premise is to stimulate innovation by ensuring that the inventor has a limited monopoly as a reward for advancing the industry. ${ }^{[2]}$ Innovative research in the pharmaceutical industry is extremely costly and time consuming. It is generally accepted that the resulting innovations are better rewarded in countries with advanced patent systems than in countries where patent protection is still lacking. Innovation leads to innovation when other inventors have the opportunity to advance the technology disclosed in patents further, and patent their own innovations in turn. However, sometimes the working of these patents may require cross-licensing between the patentees (Patents Act, ${ }^{[3]}$ section 55).

\section{Patent requirements and applications}

To be patentable an invention must be new, involve an inventive step, and have the capability of being used or applied in trade, industry or agriculture (Patents Act, ${ }^{[3]}$ section 25). The specific form and requirements of a patent application vary for each country. Generally, all patent applications can be divided into two major parts. Firstly, a patent will contain a detailed disclosure in order to enable a person of ordinary skill in the pertinent area to make and use the invention without extensive experimentation. ${ }^{[4]}$ Secondly, and most importantly, a patent contains a set of worded claims that defines the scope of the monopoly and thus the protection applied for. Whether or not a patent is granted almost always depends on whether the subject matter of the claims is novel and inventive in comparison with what came before (Patents Act, ${ }^{[3]}$ section 25).

In the pharmaceutical field, groups of patents may be granted starting with the development of a novel active pharmaceutical ingredient. For example, an active ingredient and its synthesis may be patented, followed by patents protecting the formulation of the final product containing the active ingredient and the manufacturing process of the final product. Even after the initial patent has expired, the formulation and manufacturing process of the final product may therefore still be protected, impacting on generic manufacturers.

\section{Abuse of the patent system}

South Africa (SA) is not an examining country, which means that the content of patent applications is not examined to determine whether they meet the requirements for patentability. However, lack of patentability is grounds on which an application for revocation of a patent may be lodged (Patents Act, ${ }^{[3]}$ section 61). A patent may also be revoked on grounds that the invention as illustrated or exemplified in the patent document cannot be performed or does not lead to the results and advantages set out (Patents Act, ${ }^{[3]}$ section 61). A patent has to fully disclose the invention in return for the monopoly granted.

Furthermore, the Patents Act makes provision for any interested person who is able to show that the rights in a patent are being abused to apply to the commissioner for a compulsory licence under the patent (Patents Act, ${ }^{[3]}$ section 56). The rights in a patent are deemed to be abused for various reasons. An example is that the patented invention is not being worked in SA on a commercial scale or to an adequate extent, after the expiry of a period of 4 years subsequent to the date of the application for the patent, or 3 years subsequent to the date on which that patent was sealed, whichever period expires last, and if in the opinion of the commissioner there is no satisfactory reason for such non-working (Patents Act, ${ }^{[3]}$ section 56). The Patents Act therefore contains provisions to prevent the abuse of patents.

\section{Patent infringement $v$. circumvention}

In SA, as in most countries around the world, a patent is infringed when a product or process that falls within the scope defined by the claims is made, used, offered for sale, sold or imported, without permission, in the country where the patent has been granted (Patents Act, ${ }^{[3]}$ sections 45 and 65). In order to determine whether a product falls within the defined scope of a patent, a list of essential features are isolated within the wording of the claims in the patent, and if all these essential features are present in the product or process under consideration, the patent has been infringed. ${ }^{[5,6]}$ The patentee has the right to institute proceedings for infringement in these circumstances.

The model set out above creates an interesting conundrum in the pharmaceutical industry, where competitors are provided with a detailed description of all the products that are developed, as well as a list of essential features that defines the scope of patent protection. Players in this industry sometimes devote time and money to analyse the inventions of their competitors in order to determine whether they can produce similar products with similar effects, by doing without one of the essential features that defines the scope of patent protection. If this can be achieved, a company can piggy-back on the research of a competitor without investing the same time and resources. This is known as competitive patent circumvention, which, if successfully conducted, does not lead to patent infringement and is not unlawful but may affect the medicine's quality, safety and/or efficacy. 


\section{Circumvention of patents and its effect on quality, safety and efficacy of medicines}

Registration of a medicine in SA provides the assurance that the medicine meets the quality and safety requirements and is effective for its intended purpose. The quality of a medicine includes attributes such as identity, strength and purity, which are incorporated into an approved set of standards against which the medicine is tested. ${ }^{[7]}$ If a medicine consistently meets these standards, it is a quality medicine.

Furthermore, medicines should be safe and efficacious in order for them to be acceptable for patient use. Safety is the ability of the medicine not to cause unprecedented harm or serious side-effects, when measured against the risk-benefit profile of the medicine. Side-effects of a medicine are often due to the inherent properties of the active pharmaceutical substance/s it contains ${ }^{[8]}$ Efficacy, on the other hand, is simply an expression used to determine whether the medicine is useful for its intended purpose. ${ }^{[9]}$ Efficacy therefore means that the medicine meets its therapeutic claim. ${ }^{[10]} \mathrm{A}$ combination of carefully designed, and conducted in vitro, animal and clinical studies assist in identifying undesirable and toxic effects of a medicine, and also its efficacy. ${ }^{[11]}$

Quality, safety and efficacy studies are conducted to support the registration of a medicine. The medicines regulatory authority (MRA) in SA ensures that all the requirements for quality, safety and efficacy are met before granting registration. The requirements set by the MRA often give rise to the development of innovative formulations and manufacturing procedures, which are patented separately from the active pharmaceutical ingredient. This creates a challenge for generic manufacturers who wish to manufacture a generic medicine after the expiry of the patent that protected the active pharmaceutical ingredient/s of the medicine. A new and innovative formulation or process has to be established for the generic medicine which is qualitatively and quantitatively similar to the innovator medicine without infringing the patent protecting this formulation or process.

In practice the development of these new formulations may prove troublesome. For example, a pharmaceutical patent may stipulate a specific excipient, and in an effort to circumvent the patent a generic medicine manufacturer will have to use another excipient. If an effective excipient cannot be found during product development, the product may present with both safety and efficacy issues following poor-quality formulation.

Another example is that a specific impurity limit may be claimed for an active ingredient. An effort to circumvent such a patent may result in the intentional contamination of the active ingredient to raise the quantity of the impurity above the patented limits. This intentional contamination compromises quality and violates good manufacturing and regulatory process, even if the quantity of the impurity introduced is not significant and will not present safety or efficacy concerns. Compromising quality may result in safety concerns and efficacy problems, especially in cases where patients respond differently to the same active substance and in drugs with a narrow therapeutic index.

\section{Conclusion}

The impact of patent circumvention potentially has serious implications with regard to medicine quality, safety and efficacy, even if it was intended to improve accessibility and affordability of these medicines. Although the MRA does not have any mandate with regard to patents, it has a mandate to protect the public. Efforts to circumvent patents sometimes increase the regulatory burden of monitoring product quality, safety and efficacy. Furthermore, a lack of efficacy caused by efforts to circumvent patents protecting formulations or processes may result in subtherapeutic levels of medicines, resulting in obvious health risks. For example, ineffective asthma medication may result in death, and subtherapeutic levels of antiepileptics or antibiotics will result in relapses and drug resistance, respectively. The impact of patent circumvention has far-reaching effects on public health.

Companies should therefore conduct adequate research in order to understand the effect of patent circumvention on the quality, safety and efficacy of medicine. Sufficient research is necessary to develop alternative formulations and processes, which have to be appropriately validated using production scale batches. Furthermore, sufficient stability data (including stress testing) has to be generated. These steps are necessary to ensure production of a quality product that will not during any stage of its life cycle fail in terms of quality, compromise patient safety, or be ineffective.

\section{Karen du Toit}

Honorary Associate Professor, Discipline of Pharmaceutical Sciences, School of Health Sciences, University of KwaZulu-Natal, Durban, South Africa, and owner, Pharmalaw (Pty) Ltd, Pretoria, South Africa

\section{Willem du Preez}

Intellectual Property Development Manager, Westfalia Fruit, Tzaneen, Limpopo, South Africa

\section{Silverani Padayachee}

Pharmacist, Pretoria, South Africa

\section{Corresponding author: Kdu Toit (dutoitk@ukzn.ac.za)}

1. World Intellectual Property Office (WIPO). http://www.wipo.int/patents/en/ (accessed 15 June 2015). 2. World Intellectual Property Office (WIPO). http://www.wipo.int/patent-law/en/developments/ research.html (accessed 15 June 2015)

3. Patents Act, Act No. 57 of 1978. http://www.cipc.co.za/files/9513/9452/7965/Patent_Act.pdf (accessed 15 June 2015).

4. United States Patent and Trademark Office. http://www.uspto.gov/patents-getting-started/patentbasics/types-patent-applications/nonprovisional-utility-patent\#heading-18 (accessed 15 June 2015).

5. Letraset Limited v Helios Limited 1972 (3) SA 245 (A).
6. Stauffer Chemical Co and another v Sasfan Marketing and Distribution Co 1987 (2) SA 331 (A),

7. ICH Harmonized Tripartite Guideline (Q6A). Specifications: Test Procedures and Acceptance Criteria for New Drug Substances and New Drug Products: Chemical Substances, 1999. http://www.ich.org/ for New Drug Substances and New Drug Products: Chemical Substances, 1999. http://www.ich.org/
fileadmin/Public_Web_Site/ICH_Products/Guidelines/Quality/Q6A/Step4/Q6Astep4.pdf (accessed 15 June 2015).

8. Gorog S. Drug safety, drug quality, drug analysis. J Pharm Biomed Anal 2008;48(2):247-253.

9. ICH Harmonized Tripartite Guideline (E3). Structure and Content of Clinical Study Reports, 1996. http://www.ich.org/fileadmin/Public_Web_Site/ICH_Products/Guidelines/Efficacy/E3/E3_Guideline. pdf (accessed 15 June 2015).

10. Fefer E. Pharmaceutical Legislation and Regulation. In: MDS-3:Managing Access to Medicines and Health Technologies, 3rd ed. WHO Publication, 2012. http://apps.who.int/medicinedocs/documents/ s19577en/s19577en.pdf (accessed 15 June 2015).

11. ICH Harmonized Tripartite Guideline (S7A). Safety Pharmacology Studies for Human Pharmaceuticals, 2000. http://www.ich.org/fileadmin/Public_Web_Site/ICH_Products/Guidelines/ Safety/S7A/Step4/S7A_Guideline.pdf (accessed 15 June 2015).

S Afr Med J 2015;105(11):905-906. DOI:10.7196/SAMJ.2015.v105i11.10185 